\title{
Влияние слоя GaAs, выращенного при низкой температуре, на фотолюминесценцию квантовых точек InAs
}

\author{
(C) А.Н. Косарев ${ }^{*+}$, В.В. Чалдышев ${ }^{*+}$, В.В. Преображенский ${ }^{\bullet}$, М.А. Путято, Б.Р. Семягин ${ }^{\bullet}$ \\ * Физико-технический институт им. А.Ф. Иоффре Российской академии наук, \\ 194021 Санкт-Петербург, Россия \\ + Санкт-Петербургский политехнический университет Петра Великого, \\ 195251 Санкт-Петербург, Россия \\ - Институт фризики полупроводников Сибирского отделения Российской академии наук, \\ 630090 Новосибирск, Россия \\ E-mail: chald.gvg@mail.ioffe.ru
}

(Получена 27 апреля 2016 г. Принята к печати 10 мая 2016 г.)

\begin{abstract}
Проводились исследования фотолюминесценции полупроводниковых квантовых точек InAs, поверх которых был выращен слой GaAs в низкотемпературном режиме (LT-GaAs), с использованием различных разделительных слоев или без них. Под разделительными слоями подразумеваются тонкие слои GaAs или $\mathrm{AlAs,} \mathrm{выращенные} \mathrm{при} \mathrm{нормальных} \mathrm{для} \mathrm{молекулярно-лучевой} \mathrm{эпитаксии} \mathrm{(МЛЭ)} \mathrm{температурах.} \mathrm{Прямое}$ заращивание привело к исчезновению фотолюминесценции. При использовании тонкого разделительного слоя GaAs фотолюминесценция из квантовых точек InAs частично восстановилась, но ее интенсивность оказалась на 2 порядка меньше, чем в референтном образце, в котором заращивание массива квантовых точек производилось при нормальной температуре. Использование более широкозонного AlAs в качестве материала разделительного слоя привело к усилению фотолюминесценции из квантовых точек InAs, но она все еще была более чем на порядок слабее относительно излучения референтного образца. Построена модель, учитывающая процессы генерации носителей светом, их диффузии и туннелирования из квантовых точек в слой LT-GaAs.
\end{abstract}

\section{1. Введение}

Полупроводниковые квантовые точки (ПКТ) являются важным элементом современных электронных, оптических и оптоэлектронных приборов. ПКТ характеризуются дискретным набором электронных состояний, что является важным для применения в полупроводниковых лазерах [1-3], фотодетекторах [4], ячейках памяти [5,6] и других приборах. Оптические свойства ПКТ определяются резонансным взаимодействием света с локализованными в них экситонами.

Для создания массива ПКТ InAs в объеме полупроводника GaAs обычно используется режим роста Странского-Крастанова $[7,8]$. Первые несколько монослоев InAs, осаждаемых на подложку GaAs методом молекулярно-лучевой эпитаксии (МЛЭ), создают тонкий эпитаксиальный смачивающий слой, но минимизация упругой энергии в последующих осаждаемых слоях приводит к тому, что они самоорганизуются в когерентные островки - ПКT InAs. Затем островки заращивают слоем материала матрицы, таким образом ПКТ оказываются в объеме полупроводника. Процесс формирования ПКТ можно повторить. Если толщина верхнего слоя матрицы не велика, то сформированные на поверхности такой системы ПКТ окажутся пространственно коррелированными в направлении роста с ПКТ предыдущего слоя из-за созданных ими упругих напряжений. За счет этого эффекта можно создать близкие пары и стопки ПКТ.

Обычно пленки GaAs выращиваются в установке МЛЭ при температуре $\sim 500^{\circ} \mathrm{C}$. Если снизить температуру роста до $\sim 200^{\circ} \mathrm{C}$ (низкотемпературный режим), то в пленку будет захватываться избыточное количество
As в виде точечных антиструктурных дефектов $\mathrm{As}_{\mathrm{Ga}}[9]$. После отжига в таком GaAs (low-temperature GaAs, LT-GaAs) избыточный As собирается в нановключения полуметалла As, которые в зависимости от времени отжига могут принимать размеры от единиц до десятков нанометров [9-11]. Благодаря этому материал приобретает такие уникальные свойства, как высокое удельное электрическое сопротивление, ультракороткие времена жизни носителей заряда, < 1 пс $[12,13]$, и т.д. Эти уникальные свойства могут позволить сделать более быстродействующими оптические и оптоэлектронные приборы на основе ПКТ, используя LT-GaAs $[13,14]$.

Совмещение массивов ПКТ и LT-GaAs - технологически сложная задача. Несмотря на существенную разницу в процедурах формирования, такие образцы были получены. В работах [15-17] рассматриваются структурные характеристики. Данная работа посвящена исследованию изменения фотолюминесценции (ФЛ) ПКТ InAs при заращивании массива ПКТ слоем LT-GaAs, как непосредственно, так и с использованием разделительных слоев.

\section{2. Образцы}

Исследуемые образцы были получены методом МЛЭ в установке „Катунь“. Использовалась подложка полуизолирующего GaAs (001) $\pm 0.5^{\circ}$. Первым выращивался буферный слой GaAs толщиной 0.2 мкм со скоростью 1 мкм/ч при температуре $580^{\circ} \mathrm{C}$. Массивы ПКТ формировались на поверхности роста по механизму Странского-Крастанова путем осаждения на буферный 


\begin{tabular}{|c|c|c|c|}
\hline & \multirow{4}{*}{$\begin{array}{c}\text { LT-GaAs } \\
5 \mathrm{~nm} \\
\end{array}$} & $\begin{array}{l}\text { LT-GaAs } \\
5 \mathrm{~nm}\end{array}$ & \multirow{3}{*}{$\begin{array}{c}\text { LT-GaAs } \\
5 \mathrm{~nm}\end{array}$} \\
\hline & & AlAs $5 \mathrm{~nm}$ & \\
\hline & & LT-GaAs & \\
\hline & & $100 \mathrm{~nm}$ & AlAs $5 \mathrm{~nm}$ \\
\hline & AlAs $5 \mathrm{~nm}$ & In $0.1 \mathrm{ML}$ & LT-GaAs \\
\hline \multirow{3}{*}{$\begin{array}{l}\text { GaAs } \\
30 \mathrm{~nm}\end{array}$} & \multirow{3}{*}{$\begin{array}{l}\text { LT-GaAs } \\
30 \mathrm{~nm}\end{array}$} & LT-GaAs & $100 \mathrm{~nm}$ \\
\hline & & $3 \mathrm{~nm}$ & GaAs $3 \mathrm{~nm}$ \\
\hline & & GaAs $5 \mathrm{~nm}$ & $\mathrm{AlAs} 2.5 \mathrm{~nm}$ \\
\hline InAs $3 \mathrm{ML}$ & InAs $3 \mathrm{ML}$ & InAs $3 \mathrm{ML}$ & InAs $3 \mathrm{ML}$ \\
\hline $\begin{array}{l}\mathrm{GaAs} \\
10 \mathrm{~nm}\end{array}$ & $\begin{array}{l}\mathrm{GaAs} \\
10 \mathrm{~nm}\end{array}$ & $\begin{array}{l}\mathrm{GaAs} \\
10 \mathrm{~nm}\end{array}$ & $\begin{array}{l}\mathrm{GaAs} \\
10 \mathrm{~nm}\end{array}$ \\
\hline InAs $3 \mathrm{ML}$ & InAs $3 \mathrm{ML}$ & InAs $3 \mathrm{ML}$ & InAs $3 \mathrm{ML}$ \\
\hline $\begin{array}{l}\text { Buffer } \\
\text { GaAs }\end{array}$ & $\begin{array}{l}\text { Buffer } \\
\text { GaAs }\end{array}$ & $\begin{array}{l}\text { Buffer } \\
\text { GaAs }\end{array}$ & $\begin{array}{l}\text { Buffer } \\
\text { GaAs }\end{array}$ \\
\hline $200 \mathrm{~nm}$ & $200 \mathrm{~nm}$ & $200 \mathrm{~nm}$ & $200 \mathrm{~nm}$ \\
\hline $\begin{array}{c}\text { Substrate } \\
\text { GaAs }\end{array}$ & $\begin{array}{c}\text { Substrate } \\
\text { GaAs }\end{array}$ & $\begin{array}{l}\text { Substrate } \\
\text { GaAs }\end{array}$ & $\begin{array}{c}\text { Substrate } \\
\text { GaAs }\end{array}$ \\
\hline BP1857 & BP1858 & BP2251 & BP2252 \\
\hline
\end{tabular}

Рис. 1. Схематическое изображение структуры исследуемых образцов.

слой 3 монослоев (monolayer, ML) InAs со скоростью $0.05 \mathrm{ML} / \mathrm{c}$ при температуре $460^{\circ} \mathrm{C}$. Полученные ПКТ заращивались 10 нм материала матрицы. Затем формировался еще один слой ПКТ, положение ПКТ первого и второго слоев оказывалось коррелированным [15]. Во всех исследуемых образцах ПКТ имели описанное выше пространственное расположение. Исследуемые образцы схематически изображены на рис. 1.

Референтный образец ВР1857 содержал только два слоя ПКТ InAs, покрытых защитным слоем GaAs толщиной 30 нм, выращенным при обычной температуре. В образце ВР1858 аналогичные па́ры ПКТ InAs были непосредственно заращёны модифицирующим слоем LT-GaAs при $200^{\circ} \mathrm{C}$ толщиной 30 нм. Чтобы при отжиге избыточный As не диффундировал из слоя LT-GaAs на поверхность, он был покрыт закрывающим слоем AlAs толщиной 5 нм, который играет роль диффузионного барьера. Для защиты от окисления AlAs был покрыт слоем GaAs толщиной 5 нм. Результатам просвечивающей электронной микроскопии этой структуры посвящена статья [15].

Были изготовлены еще два образца, ВР2251 и ВР2252, отличающиеся от ВР1858 тем, что между массивом ПКТ и модифицирующим слоем LT-GaAs добавлялись дополнительные разделительные слои GaAs и AlAs + GaAs соответственно. В этих образцах толщина слоя LT-GaAs была увеличена до 100 нм, а закрывающий слой остался неизменным. Результаты исследований этих структур методом просвечивающей электронной микроскопии обсуждаются в работах $[16,17]$.

\section{3. Методика эксперимента}

Исследовались спектры ФЛ ПКТ. Для возбуждения ФЛ использовался твердотельный лазер KLM-532-х с длиной волны излучения 532 нм. Отражением излучения лазера от брэгговского зеркала осуществлялась фильтрация первой гармоники 1064 нм. Образец помещался в стеклянный криостат и находился в парах жидкого азота на расстоянии $\sim 0.5$ см от его поверхности. Поддерживалась температура $\sim 100 \mathrm{~K}$. Криостат был установлен таким образом, что образец находился в фокусе входного отверстия двухрешеточного монохроматора ЛОМО СДЛ-1, на выходе которого находился германиевый фотодиод ФД-10ГА. В монохроматоре были установлены дифракционные решетки 300 штрихов/мм. Сигнал с фотодиода попадал на синхронный детектор Anfatec USB LockIn 250, который также модулировал излучение лазера частотой 320 Гц. Положение дифракционных решеток монохроматора контролировалось шаговым двигателем через АЦП/ЦАП фирмы National Instruments (модель USB 6229). Падающая волна была поляризована под углом $50^{\circ}$ к поверхности образца, соответственно доли $s$ - и $p$-поляризации в интенсивности пучка составляли 58.5 и $41.5 \%$. Измерения проходили в диапазоне длин волн 950-1200 нм при рабочем диапазоне дифракционных решеток 800-2000 нм.

\section{4. Результаты}

Спектры ФЛ референтного, а также трех неотожженных образцов с модифицирующим слоем LT-GaAs и различными разделительными слоями изображены на рис. 2. Кривая 1 соответствует спектру ФЛ референтного образца ВP1857, где два слоя ПКТ InAs закрыты слоем GaAs,

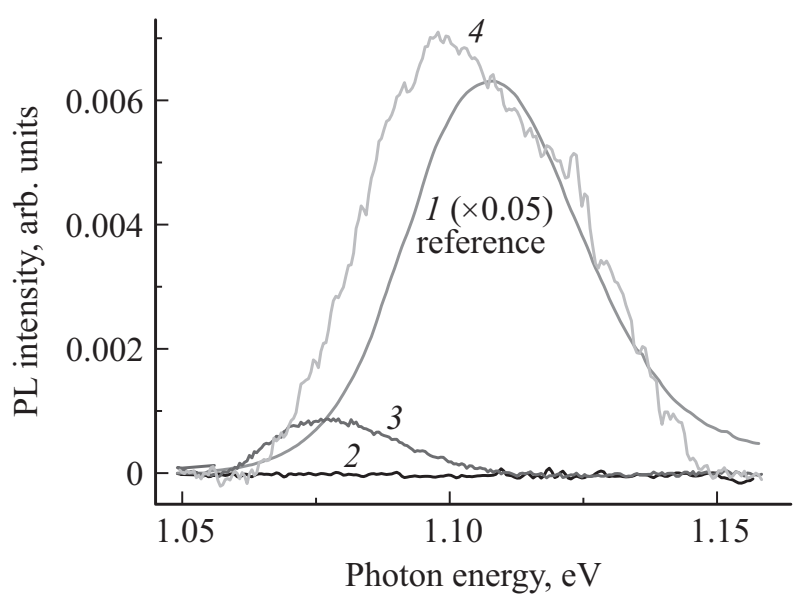

Рис. 2. Спектры фотолюминесценции (PL) образцов с двумя слоями полупроводниковых квантовых точек InAs в GaAs при различных разделительных слоях между массивом ПКТ и LT-GaAs. 1 - референтный образец (масштаб уменьшен в 20 раз), 2 - образец без разделительного слоя, 3 - образец с разделительным слоем GaAs толщиной 5 нм, 4 - образец с разделительным слоем GaAs + AlAs. Температура измерений $\sim 100 \mathrm{~K}$. 
Основные характеристики ФЛ образцов.

\begin{tabular}{l|c|c|c|c}
\hline \multicolumn{1}{c|}{ Образец } & \multicolumn{2}{|c|}{ ВР1857 } & BР2251 & BР2252 \\
\hline Спектральная ширина щели, 10 ${ }^{-3}$ эВ & 4 & 6 & 6 & 4 \\
Энергия максимума ФЛ, эВ & 1.109 & 1.109 & 1.077 & 1.098 \\
Интенсивность в максимуме, отн.ед. & 0.063 & 0.126 & $8.8 \cdot 10^{-4}$ & 0.0035 \\
Ширина на половине высоты, эВ & 0.038 & 0.039 & 0.028 & 0.046 \\
Интегральная светимость, отн. ед. & 2.39 & 4.91 & 0.025 & 0.16
\end{tabular}

при обычной температуре. Спектр имеет наибольшую интенсивность относительно остальных. Максимуму интенсивности соответствует энергия 1.107 эВ. Ширина на половине высоты составляет 38 мэВ. Имеется небольшое плечо в области высоких энергий, по-видимому, связанное с возбужденным состоянием в ПКТ InAs при энергии 1.17 эВ.

Кривая 2 является спектром ФЛ образца с модифицирующим слоем LT-GaAs, выращенным при низкой температуре без каких-либо разделительных слоев. Интенсивность ФЛ в этом случае оказалась ниже предела чувствительности приборов. При добавлении между ПКТ и модифицирующим слоем LT-GaAs разделительного слоя GaAs (образец ВР2251) ФЛ регистрируется (рис. 2, кривая 3), однако ее интенсивность в максимуме в 143 раза меньше интенсивности референтного образца. Форма линии ФЛ схожа с формой линии референтного образца, но вместо плеча в области высоких энергий интенсивность плавно уменьшается. Положение максимума спектра ФЛ образца соответствует энергии 1.075 эВ, т.е. смещено относительно регистрируемого для референтного образца в сторону меньших энергий. При этом полная ширина линии на полувысоте составляет 0.028 эВ (при 0.038 эВ в референтном образце). Кривая 4 на рис. 2 соответствует ФЛ образца ВР2252 с разделительным слоем AlAs. Интенсивность ФЛ в максимуме возрастает в 4 раза относительно случая с разделительным слоем GaAs BP2251, но при этом остается в 36 раз слабее, чем в референтном образце. Максимум все еще смещен в область низких энергий относительно регистрируемого для референтного образца ВР1857 $(1.109 \rightarrow 1.098$ эВ), но значительно меньше. Форма спектра достаточно близка к форме спектра исходного образца, но плечо в области высоких энергий отсутствует. Края всех спектров в области низких энергий совпадают. Основные характеристики спектров ФЛ представлены в таблице. Отметим, что в связи с существенной разницей в интенсивностях спектры ФЛ записывались при различной спектральной ширине щели монохроматора, соответствующей 4 или 6 мэВ в исследованном диапазоне длин волн.

\section{5. Обсуждение результатов}

Процессы, ответственные за ФЛ из ПКТ InAs и за изменение формы спектров в исследованных образцах, схематически изображены на рис. 3. Рассмотрим их подробнее далее.

Из рис. 2 видно, что референтный образец, не содержащий слоев LT-GaAs, обладает высокой интенсивностью ФЛ. Это свидетельствует о высоком кристаллическом совершенстве образца и отсутствии дефектов структуры, связанных с формированием пар ПКТ InAs по механизму Странского-Крастанова и последующим заращиванием при $580^{\circ} \mathrm{C}$.

После заращивания ПКТ слоем LT-GaAs (образец ВР1858) ФЛ исчезает, что видно из кривой 2 на рис. 2. Исчезновение ФЛ не может быть связано с разрушением (диффузионным перемешиванием) ПКТ, так как температура выращивания LT-GaAs на $260^{\circ} \mathrm{C}$ ниже температуры образования ПКТ. В работе [15] было показано, что при прямом заращивании происходит генерация дислокационных дефектов на границе ПКТ и LT-GaAs, вызываемая концентрацией механических напряжений вблизи ПКТ и особенностями кинетики роста GaAs при низкой температуре. Появление дефектов структуры уже на стадии роста приводит к исчезновению ФЛ.

Как показали электронно-микроскопические исследования [16], при использовании разделительного слоя GaAs между ПКТ и LT-GaAs генерации дефектов при низкотемпературном заращивании не происходит. Результаты микроскопии согласуются с появлением ФЛ в образце ВР2251 (рис. 2, кривая 3). Однако заращивание тонким разделительным слоем GaAs, а затем слоем

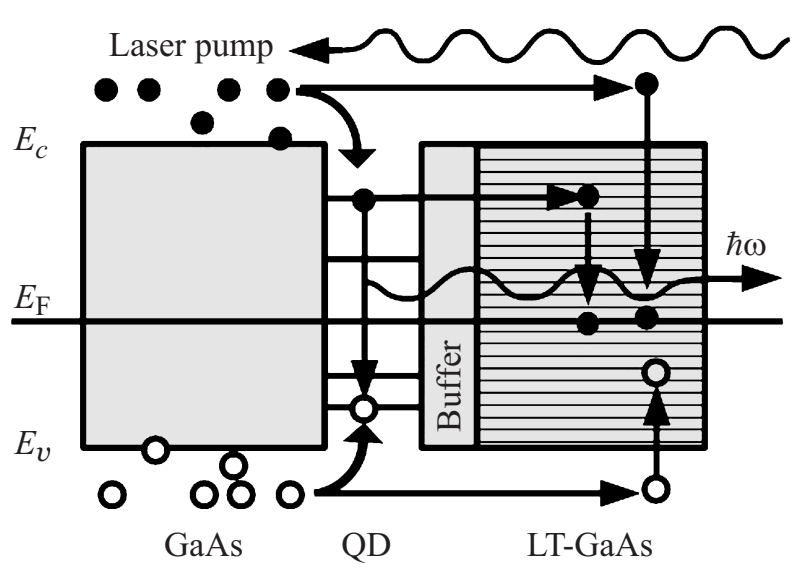

Рис. 3. Схематическое изображение процессов, происходящих с неравновесными носителями в системе с ПКТ (QD) и слоем LT-GaAs. 
LT-GaAs привело к изменению спектра ФЛ ПКТ. Положение максимума оказалось смещено, а интенсивность в максимуме на 2 порядка меньше, чем в референтной структуре ВР1857. Разберем возможные причины этого явления.

Первая причина изменения интенсивности ФЛ изменение освещенности. В образце ВP2251 ПКТ InAs находятся в 4 раза дальше от поверхности, чем в референтном образце. Коэффициент поглощения в $\mathrm{GaAs}$ излучения с длиной волны $532 \mathrm{Hм}$ составляет $\alpha=7 \cdot 10^{4} \mathrm{~cm}^{-1}[18]$. Для LT-GaAs эта величина coставляет $\alpha=8.6 \cdot 10^{4} \mathrm{~cm}^{-1}[19]$. Закон Бугера-Ламберта-Бера позволяет вычислить интенсивность света при прохождении через поглощающую среду:

$$
I(x)=I_{0} e^{-\alpha x},
$$

где $x$ - путь света в веществе, $I_{0}-$ интенсивность входящего излучения. В референтном образце из-за поглощения до массива ПКТ доходит $80.5 \%$ возбуждающего излучения лазера, попавшего в образец. В образце ВР2251 до массива ПКТ доходит только 37.5\%. При вычислении учитывалось, что свет падал на образец под углом $45^{\circ}$ и из-за преломления распространялся внутри образца под углом $11^{\circ}$.

Второй эффект, который оказывает влияние на интенсивность освещения массива ПКТ - это отражение света от границ раздела слоистой структуры образца ВР2251. Рассматривая коэффициенты отражения в поглощающих средах, необходимо использовать комплексные коэффициенты преломления. Мнимая часть коэффициента преломления $k$ связана с коэффициентом поглощения соотношением

$$
k=2 \alpha \frac{c}{\omega}=\frac{\alpha \lambda}{\pi},
$$

где $c-$ скорость света, $\omega-$ частота, $\lambda-$ длина волны.

Для света с длиной волны $532 \mathrm{Hм}$ в $\mathrm{GaAs}$ коэффициент преломления $n=4.1+1.18 i$, для LT-GaAs $n=4.1+1.46 i$ и для A1As $n=3.22$. Коэффициенты отражения от границ раздела определяются по формулам Френеля для $s$ - и $p$-поляризации:

$$
\begin{gathered}
R_{s}=\left|\frac{n_{1} \cos \left(\theta_{1}\right)-n_{2} \cos \left(\theta_{2}\right)}{n_{1} \cos \left(\theta_{1}\right)+n_{2} \cos \left(\theta_{2}\right)}\right|^{2}, \\
R_{p}=\left|\frac{\sin \left(2 \theta_{1}\right)-\sin \left(2 \theta_{2}\right)}{\sin \left(2 \theta_{1}\right)+\sin \left(2 \theta_{2}\right)}\right|^{2},
\end{gathered}
$$

где $R_{s}$ - коэффициент отражения $s$-поляризованной волны, $R_{p}$ - коэффициент отражения $p$-поляризованной волны, $n_{1}$ - коэффициент преломления среды, из которой падает свет, $\theta_{1}$ - угол падения, отсчитанный от нормали, $n_{2}$ - коэффициент преломления среды, в которую проходит свет, $\theta_{2}-$ угол преломления, отсчитанный от нормали.

Для интенсивностей прошедшей и отраженной волн

$$
R+T=1
$$

$R-$ коэффициент отражения, $T-$ коэффициент прохождения.
Коэффициенты пропускания $T$ границ раздела сред: воздух-GaAs, $47.9 \%$ для $s$-поляризации, $79.2 \%$ для $\quad p$-поляризации; воздух-LT-GaAs $46.6 \%$ для $s$-поляризации, 79.2\% для $p$-поляризации. Коэффициент прохождения границы раздела LT-GaAs-AlAs 94.6\% для $s$-поляризации, 98.7\% для $p$-поляризации. Коэффициент прохождения границы раздела LT-GaAs-GaAs составляет $\quad 99.9 \%$ для $\quad$ s-поляризации, $100 \%$ для p-поляризации.

Исходный луч был поляризован под углом $50^{\circ}$ к поверхности, т.е. 58.5\% интенсивности несет $s$-поляризация и $41.5 \%$ интенсивности несет $p$-поляризация. С учетом потерь за счет отражения от поверхности и всех границ раздела до ПКТ доходит 60.8\% падающей интенсивности в референтном образце и $56.4 \%$ в образце ВР2251. Свет, отразившийся от обеих границ раздела LT-GaAs-AlAs, а затем отразившийся от поверхности, также достигает ПКТ. Интенсивность прошедших лучей, дважды испытавших отражение, составляет в сумме $1.5 \%$ от интенсивности падающего луча.

В отличие от обычного стехиометрического GaAs, LT-GaAs поглощает излучение ПКT InAs в области 1.1 мкм [20]. Это связано с наличием в LT-GaAs большой концентрации антиструктурных дефектов мышьяка [21]. Для учета этого явления мы измерили оптическое пропускание исследованных образцов в диапазоне длин волн 900-1500 нм. Оказалось, что пропускание фотонов с энергией 1.11 эВ для образцов ВР2251 и ВР2252 со слоем LT-GaAs толщиной 108 и 105 нм соответственно понижено до 93.6 и 93\% по сравнению с референтным образцом.

С учетом эффектов отражения и поглощения интенсивность возбуждающего излучения, доходящая до ПКТ в референтном образце, составляет 49\% от интенсивности падающего света, в образце ВР2251 $21.5 \%$, в образце ВР2252 - 21.1\%. Таким образом, в образце BP2251 в области ПКТ InAs скорость генерации неравновесных носителей заряда в 2.32 раза ниже, чем в референтном образце; в образце ВР2252 в области ПКТ скорость генерации в 2.33 раза ниже.

Таким образом, снижение интенсивности ФЛ из ПКТ в образце ВР2251 не объясняется поглощением и отражением возбуждающего и излучаемого света. Кроме того, коэффициенты поглощения и отражения мало изменяются в рассматриваемом интервале энергий фотонов шириной 0.1 эВ, поэтому поглощение в слое LT-GaAs не объясняет столь сильное изменению формы спектра излучения из ПКТ InAs.

Причина наблюдаемого изменения интенсивности и формы спектра ФЛ ПКТ InAs в образце ВР2251 и полное гашение такой ФЛ в образце ВР1858 может состоять в появлении дополнительного специфического канала безызлучательной рекомбинации носителей заряда. Если в образце ВР1858 таким каналом может быть рекомбинация на дислокационных дефектах, то в образце ВР2251 быстрая безызлучательная рекомбинация не может быть связана с дефектами структуры, 
поскольку электронно-микроскопические исследования этого образца показали, что использование разделительного слоя GaAs толщиной 5 нм позволяет полностью избежать формирования таких дефектов [17].

Неравновесные носители заряда захватываются в ПКТ из окрестности смачивающего слоя InAs; следовательно, интенсивность ФЛ можно считать пропорциональной концентрации неравновесных носителей матрицы в области смачивающего слоя. Определив стационарное распределение неравновесных носителей, можно оценить изменение ФЛ из ПКТ InAs. Распределения неравновесных носителей определяются конкуренцией процессов их генерации возбуждающим светом, безызлучательной рекомбинации на дефектах, захвата и излучательной рекомбинации на ПКТ и диффузионного обмена с прилегающими областями гетероструктуры.

В работе [22] рассматривалась модель возбуждения носителей в полупроводнике генерирующей плоскостью в случае, когда на поверхности происходит рекомбинация со скоростью $s$. Стационарное распределение неравновесных носителей в этой модели определено выражением

$$
f(x, h)=\frac{1}{2}\left[e^{-|x-h| / L_{d}}-\frac{s-v_{d}}{s+v_{d}} e^{-(x+h) / L_{d}}\right],
$$

где $x$ - расстояние от поверхности, $h$ - положение генерирующей плоскости, $v_{d}$ - диффузионная скорость, $L_{d}$ - длина диффузии, $s-$ скорость рекомбинации.

Эта модель представляется применимой к рассматриваемой задаче. В связи с низкой интенсивностью ФЛ можно полагать, что захват носителей в смачивающий слой и ПКТ InAs из барьера GaAs происходит достаточно медленно [23] относительно скоростей рекомбинации в LT-GaAs [11], поэтому сильных возмущений в пространственное распределение носителей этот процесс не вносит. Возбуждение носителей в образце происходит светом лазера, интенсивность возбуждения постоянна в любой плоскости, параллельной поверхности, и описывается законом Бугера-Ламберта-Бера (1). Стационарное распределение концентрации неравновесных носителей для рассматриваемой системы описывается выражением

$$
\begin{aligned}
g(x) & =\int_{0}^{+\infty} e^{-\alpha h} f(x, h) d h \\
& =\frac{I}{2}\left\{\frac{2 \kappa}{\kappa^{2}-\alpha^{2}} e^{-\alpha x}-\left(\frac{1}{\kappa-\alpha}+\frac{s-v_{d}}{s+v_{d}} \frac{1}{\kappa+\alpha}\right) e^{-\kappa x}\right\},
\end{aligned}
$$

где $\alpha-$ коэффициент поглощения света в среде, $\kappa-$ величина, обратная длине диффузии.

Для оценки изменения интенсивности ФЛ рассчитаем, на сколько изменится количество неравновесных носителей около квантовых ям InAs. При вычислении интенсивностей использовались следующие параметры: коэффициент поглощения $\alpha=7 \cdot 10^{4} \mathrm{~cm}^{-1}[18]$, коэффициент диффузии $D=43 \mathrm{~cm}^{2} \cdot \mathrm{c}^{-1}[12,24]$. Скорость поверхностной рекомбинации GaAs можно оценить как $s=10^{5} \mathrm{~cm} / \mathrm{c}$ [25]. Скорость рекомбинации на поверхности между LT-GaAs и GaAs сильно зависит от технологического процесса роста конкретного образца. Порядок этой скорости можно оценить, считая, что рекомбинация происходит в первую очередь за счет малого времени жизни $\tau$ неравновесных носителей в LT-GaAs, и используя соотношение

$$
s=\frac{d}{2 \tau} .
$$

Для оценки используются следующие величины: характерное время жизни в LT-GaAs $\tau=275$ фс [12], характерный масштаб - расстояние от поверхности рекомбинации до ближайшей квантовой ямы $d=5$ нм. В таком случае в образце ВР2251 скорость поверхностной рекомбинации на границе раздела GaAs-LT-GaAs будет равна $s=9100 \mathrm{M} / \mathrm{c}$. За счет рекомбинации на поверхности ФЛ снизится в 13.2 раз относительно референтного образца с учетом эффектов отражения и поглощения структурой входящего и исходящего света.

Использовать такую оценку для образца ВР2252 не следует, так как буферный слой AlAs более широкозонный и создает барьер для носителей. Помимо изменения потока света в области ПКТ, вклад в изменение ФЛ вносят процессы рекомбинации на поверхности между AlAs и LT-GaAs, а также дефекты. Известно, что в совокупности интенсивность ФЛ снижается в 14.95 раз, причем в 2.32 раза поток света снижается за счет поглощения и отражения структурой образца. Таким образом, поверхностная рекомбинация и дефекты ослабят ФЛ в 6.42 раза. Не имея возможности разделить вклад этих эффектов, мы можем ввести эффективную скорость рекомбинации. Численно варьируя скорость поверхностной рекомбинации в выражении (7), наблюдаемое ослабление ФЛ получаем при эффективной скорости поверхностной рекомбинации $s^{*}=10475 \mathrm{M} / \mathrm{c}$.

На рис. 4, $a$ изображен спектр ФЛ образца ВР2251, деленный на спектр образца ВР1857; на рис. 4,bспектр ФЛ образца ВР2251, деленный на спектр образца ВР2252. Здесь мы не учитываем обсуждаемые выше эффекты, отношение характеризует только вклад эффектов туннелирования. Столь сильное изменение формы спектра может объясняться процессами туннелирования, которые очень чувствительны к энергии носителей. Туннелирование может происходить из ПКТ в континуум состояний LT-GaAs, при этом GaAs будет играть роль барьера. Электроны, попавшие в слой LT-GaAs, безызлучательно рекомбинируют за фемтосекундные времена [12]. Схематически эта идея изображена на рис. 3. Рекомбинация носителей, находящихся в ПКТ, может протекать по двум каналам: оптическая рекомбинация за время $\tau_{\text {opt }}$ и туннельная за время $\tau_{\text {tun. }}$. Тогда вероятность оптической рекомбинации будет определяться выражением

$$
P=\frac{1 / \tau_{\mathrm{opt}}}{1 / \tau_{\mathrm{opt}}+1 / \tau_{\mathrm{tun}}}=\frac{1}{1+\tau_{\mathrm{opt}} / \tau_{\mathrm{tun}}} .
$$

Обратное время туннелирования - функция энергии $E$ частицы. Ее значение можно представить как туннель- 

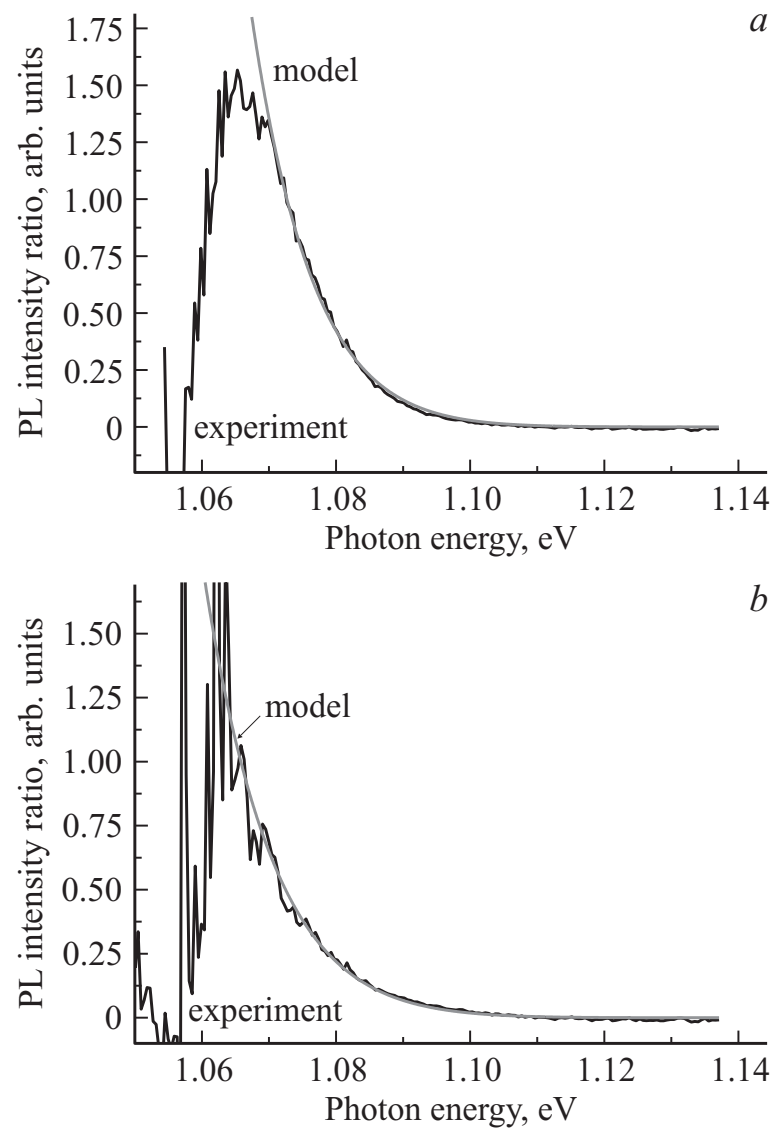

Рис. 4. $a$ - спектр фотолюминесценции (PL) образца ВР2251, поделенный на спектр референтного образца, сравнивается с теоретической зависимостью. $b-$ спектр фотолюминесценции (PL) образца BP2251, поделенный на спектр образца BP2252, сравнивается с теоретической зависимостью. Спектры перенормированы для исключения вклада перераспределения носителей.

ную прозрачность барьера, деленную на квазиклассический период движения частицы в яме:

$$
\frac{1}{\tau_{\text {tun }}}=\frac{1}{T_{0}} \exp \left(-2 \frac{a}{\hbar} \sqrt{2 m(U-E)}\right),
$$

где $a$ - толщина барьера, $U-$ его высота, $m-$ эффективная масса, $T_{0}-$ квазиклассический период колебания частицы в потенциальной яме.

Так как отношение излучательной рекомбинации к времени туннелирования $\gg 1$, вероятность туннелирования можно представить в форме

$$
P(E)=\frac{T_{0}}{\tau_{\mathrm{opt}}} \exp \left[2 \frac{a}{\hbar} \sqrt{2 m(U-E)}\right] .
$$

Для подгонки используем функцию

$$
P(E)=A \exp \left(B \sqrt{U-\frac{6}{7} E}\right) .
$$

Множитель 6/7 перед энергией электрона учитывает, что энергия фотона равна разности энергий уровней электрона и дырки в квантовой яме.
Время жизни возбуждения в ПКТ составляет $\sim 1$ нс [26]. Квазиклассический период частицы в ПКТ можно оценить из неопределенности энергия-время при средней энергии излучения 1.1 эВ как $T_{0} \approx 3 \cdot 10^{-16} \mathrm{c}$. Их отношение равно $3 \cdot 10^{-7}$. Положим множитель перед экспонентой равным $A=3 \cdot 10^{-7}$, а высоту и длину барьера будем варьировать.

При сравнении с референтным образцом (рис. 4,a) наилучшее согласие достигается при значении подгоночных параметров $B=63.31, U=0.976$ эВ. Зная эти параметры, можно оценить эффективную ширину барьера. Данная модель оценивает ее в 24.5 нм при проектируемой толщине барьерного слоя 5 нм. Следует понимать, что полученная оценка длины туннелирования является эффективной длиной в силу простоты модели. Высота барьера для электрона, отсчитываемая от энергии дырки, оценивается в 1.3 эВ. Увеличение высоты барьера в образце ВP2252 с разделительным слоем AlAs + GaAs ведет к исчезновению эффектов туннелирования, форма спектра восстанавливается, что согласуется с предсказаниями модели туннелирования. Отношение спектров на рис. $4, b$ наилучшим образом аппроксимируется функцией (12) при $B=59.6, U=0.977$ эВ, что находится в согласии с предыдущим случаем. Эффективная длина туннелирования составляет $23.1 \mathrm{Hм}$.

Рекомбинация носителей из ПКТ в слое LT-GaAs также вносит большой вклад в изменение интенсивности ФЛ образца ВР1858, так как в нем отсутствует какой-либо буферный слой. Таким образом, в исчезновение ФЛ в этом образце вносят вклад следующие процессы: отражение и поглощение света структурой, перераспределение неравновесных носителей, а также туннелирование носителей из ПКТ в слое LT-GaAs.

Рассмотрим спектр ФЛ образца ВР2252, представленного на рис. 2 (кривая 4). Несмотря на то что форма спектра схожа с формой спектра референтного образца (рис. 2, кривая 1), имеются небольшие различия в положении максимума, а также интегральная светимость меньше в 14.95 раза. Из-за отражения от слоистой структуры до зоны генерации носителей доходит меньше света, чем в референтном образце ВР1857. Также снижается эффективность вывода света из образца. Оба эти эффекта снижают интенсивность ФЛ в 2.33 раза. Остальное изменение интенсивности ФЛ происходит из-за перераспределения неравновесных носителей, а также из-за наличия дефектов. Рассогласование максимумов спектров ФЛ незначительно и может быть связано с тем, что образцы были выращены в немного различных условиях. В статье [27] показано, что заращивание ПКТ материалом может снижать количество ПКТ. При заращивании ПКТ различным закрывающим слоем эти эффекты могут проявляться по-разному, меняя тем самым распределение ПКТ по размерам. Также по данным микроскопии [16] известно, что при заращивании ПКТ слоем AlAs происходит генерация дефектов. Микроскопия также показывает, что слой AlAs утончается на 
вершинах ПКТ, что может являться причиной туннелирования носителей из ПКТ в слой LT-GaAs. Отношение спектров ФЛ образцов ВР2252 и ВР2251 имеет слегка схожий вид с отношением для референтного образца и образца ВР2251. Это отношение стремится не к нулю, а к постоянному значению. Процессы туннелирования могут вносить вклад только в изменение интенсивности ФЛ из больших ПКТ, над которыми барьер AlAs становится тоньше. Еще одной причиной изменения спектра ФЛ может быть незначительная диффузия AlAs в материал ПКТ, что может изменить положение уровней.

\section{6. Заключение}

Исследовались спектры ФЛ образцов, в которых двухслойные пространственно-коррелированные ПКТ были закрыты слоем LT-GaAs. В зависимости от наличия и вида разделительного слоя между ПКТ и слоем LT-GaAs были получены различные результаты. ФЛ отсутствует в образце, где LT-GaAs был выращен непосредственно поверх массива ПКТ. Это объясняется тем, что при прямом заращивании формируется большое количество дислокаций. На основании результатов этой работы можно также говорить, что в отсутствие разделительного слоя сильно снижается концентрация носителей в окрестности массивов ПКТ, а носители, захваченные в ПКТ, туннелируют в слой LT-GaAs, где безызлучательно рекомбинируют. При наличии разделительного слоя GaAs дислокации не появляются, а процессы туннелирования меняют форму спектра ФЛ ПКТ, но не подавляют ФЛ полностью. Мы создали модель, которая качественно показывает, что изменение спектра ФЛ происходит именно за счет процессов туннелирования. Также была построена модель, которая описывает концентрацию неравновесных носителей, возбуждаемых светом лазеpa, при наличии поверхности, на которой происходит рекомбинация неравновесных носителей. ФЛ образца с разделительным слоем AlAs интенсивнее, чем образца с разделительным слоем GaAs, за счет того, что AlAs более широкозонный. Тем не менее из-за наличия разделительного слоя AlAs происходит формирование дислокаций, которые не позволяют получить бо́льшие интенсивности ФЛ.

Работа выполнена при поддержке программы фундаментальных исследований Президиума РАН „Фундаментальные и прикладные проблемы фотоники и физика новых оптических материалов“.

\section{Список литературы}

[1] H. Liu, T. Wang, Q. Jiang, R. Tutu, F. Pozzi, A. Seeds. Nature Photonics, 5, 416 (2011).

[2] С. Михрин, А. Жуков, А. Ковш, Н. Малеев, В. Устинов, Ю. Шерняков, И Каяндер, Е. Кондратьева, Д. Лившиц, И. Тарасов, М. Максимов, А. Цацульников, Н. Леденцов, П. Копьев, Д. Бимберг, Ж. Алфёров. ФТП, 34, 117 (2000).
[3] N. Ledentsov. Semicond. Sci. Technol., 26, 014001 (2011).

[4] J. Wu, S. Chen, A. Seeds, H. Liu. J. Phys. D: Appl. Phys., 48, 363001 (2015).

[5] A. Marent, T. Nowozin, M. Geller, D. Bimberg. Semicond. Sci. Technol., 26, 014026 (2011).

[6] M. Kroutvar, Y. Ducommun, D. Heiss, M. Bichler, D. Schuh, G. Abstreiter, J.J. Finley. Nature, 81, 432 (2004).

[7] F. Ferdos, M. Sadeghi, Q.X. Zhao, S.M. Wang, A. Larsson. J. Cryst. Growth, 227, 1140 (2001).

[8] H. Liu, B. Xu, D. Ding, Y. Chen, J. Zhang, J. Wu, Z. Wang. J. Cryst. Growth, 227, 1005 (2001).

[9] V. Chaldyshev. Mater. Sci. Engin. B, 88, 195 (2002).

[10] M. Melloch, J. Woodall, E. Harmon, N. Otsuka, F. Pollak, D. Nolte, R. Feenstra, M. Lutz. Ann. Rev. Mater. Sci., 25, 547 (1995).

[11] Н. Берт, А. Вейнгер, М. Вилисова, С. Голощапов, И. Ивонин, С. Козырев, А. Куницын, Л. Лаврентьева, Д. Лубышев, В. Преображенский, Б. Семягин, В.В. Третьяков, В. Чалдышев, М. Якубеня. ФТТ, 35, 2609 (1993).

[12] А. Пастор, У. Прохорова, П. Сердобинцев, В. Чалдышев, М. Яговкина. ФТП, 47, 1144 (2013).

[13] D. Nolte. J. Appl. Phys., 85, 6259 (1999).

[14] L. Desplanque, J. Lampin, F. Mollot. Appl. Phys. Lett., 84, 2049 (2004).

[15] В. Неведомский, Н. Берт, В. Чалдышев, В. Преображенский, М. Путято, Б. Семягин. ФТП, 43, 1662 (2009).

[16] В. Неведомский, Н. Берт, В. Чалдышев, В. Преображенский, М. Путято, Б. Семягин. ФТП, 45, 1642 (2011).

[17] В.Н. Неведомский, Н.А. Берт, В.В. Чалдышев, В.В. Преображенский, М.А. Путято, Б.Р. Семягин. ФТП, 47, 1196 (2013).

[18] H. Casey, D. Sell, K. Wecht. J. Appl. Phys., 46, 250 (1975).

[19] S. Dankowski, D. Streb, M. Ruff, P. Kiesel, M. Kneissl, B. Knupfer, G. Dohler. Appl. Phys. Lett., 68, 37 (1996).

[20] N. Bert, V. Chaldyshev, A. Kunitsyn, Yu. Musikhin, N. Faleev, V. Tretyakov, V. Preobrazhenskii, M. Putyato, B. Semyagin. Appl. Phys. Lett., 70, 3146 (1997).

[21] X. Liu, A. Prasad, J. Nishio, E.R. Weber, Z. Liliental-Weber, W. Walukiewicz. Appl. Phys. Lett., 67, 279 (1995).

[22] W. Van Roosbroeck. J. Appl. Phys., 26, 380 (1955).

[23] P.W.M. Blom, C. Smit, J.E.M. Haverkort, J. Wolter. Phys. Rev. B, 47, 2072 (1993).

[24] P. Loukakos, C. Kalpouzos, I. Perakis, Z. Hatzopoulos, M. Sfendourakis, G. Kostantinidis, C. Fotakis. J. Appl. Phys., 91, 9863 (2002).

[25] D. Aspnes. Surf. Sci., 132, 406 (1983).

[26] L. Kong, Z. Wu, Z.C. Feng, I.T. Ferguson. J. Appl. Phys., 101, 126101 (2007).

[27] F. Ferdos, S. Wang, Y. Wei, A. Larsson, M. Sadeghi, Q. Zhao. Appl. Phys. Lett., 81, 1195 (2002).

Редактор Л.В. Шаронова 


\title{
Influence of GaAs layer grown at low \\ temperature on InAs quantum dots photoluminescence
}

A.N. Kosarev*+, V.V. Chaldyshev*+, V.V. Preobrazhenskii $\bullet^{\bullet}$ M.A. Putyato ${ }^{\bullet}$, B.R. Semyagin ${ }^{\bullet}$

* loffe Institute,

194021 St. Petersburg, Russia

+ Peter the Great Polytechnic University, 195251 St. Petersburg, Russia

- Institute of Semiconductor Physics,

Siberian Branch of Russian Academy of Sciences,

630090 Novosibirsk, Russia

\begin{abstract}
We studied photoluminescence from InAs semiconductor quantum dots (SQDs), which were overgrown by GaAs at low temperature regime (LT-GaAs) with or without buffer layers. Direct overgrowth made the photoluminescence to disappear. The use of a thin GaAs buffer layer led to partial recovery of the photoluminescence from the InAs SQDs, nevertheless it was by two orders less than in the basic sample where the array of SQDs was overgrown at normal temperature. The use of AlAs with large band gap as the buffer layer led to some enhancement of the photoluminescence from InAs SQDs, but it remained weaker by one order of magnitude compared to the basic sample. We built a model, which accounts for optical generation, diffusion and tunneling of carriers from the SQDs to the LT-GaAs layer.
\end{abstract}

